\title{
$\gamma$-Tocotrienol does not substantially protect DS neurons from hydrogen peroxide-induced oxidative injury
}

Sue-Mian Then ${ }^{1 *}$, Coral Sanfeliu², Gapor M Top ${ }^{4}$, Wan Zurinah Wan Ngah ${ }^{1,3}$ and Musalmah Mazlan ${ }^{1,3}$

\begin{abstract}
Background: Down syndrome (DS) neurons are more susceptible to oxidative stress and previous studies have shown that vitamin E was able to reduce oxidative stress and improve DS neurons' viability. Therefore, this study was done to investigate the protective role of $\gamma$-tocotrienol $(\gamma T 3)$ in DS neurons from hydrogen peroxide $\left(\mathrm{H}_{2} \mathrm{O}_{2}\right)$ -induced oxidative stress. The pro-apoptosis tendency of $\gamma T 3$ was compared to $\alpha$-tocopherol $(\alpha T)$ in non-stress condition as well.
\end{abstract}

Methods: Primary culture of DS and euploid neurons were divided into six groups of treatment: control, $\mathrm{H}_{2} \mathrm{O}_{2}, \gamma \top 3$ pre-treatment with $\mathrm{H}_{2} \mathrm{O}_{2}, \gamma T 3$ only, $\alpha$ T pre-treatment with $\mathrm{H}_{2} \mathrm{O}_{2}$ and $\alpha$ T only. The treatments were assessed by MTS assay and apoptosis assay by single-stranded DNA (ssDNA) apoptosis ELISA assay, Hoechst and Neu-N immunofluorescence staining. The cellular uptake of $\gamma T 3$ and $\alpha T$ was determined by HPLC while protein expressions were determined by Western blot. Comparison between groups was made by the Student's t test, one-way ANOVA and Bonferroni adjustment as well as two-way ANOVA for multiple comparisons.

Results: One day incubation of $\gamma T 3$ was able to reduced apoptosis of DS neurons by $10 \%$, however $\gamma \top 3$ was cytotoxic at longer incubation period (14 days) and at concentrations $\geq 100 \mu \mathrm{M}$. Pre-treatment of $\alpha \mathrm{T}$ and $\gamma \mathrm{T} 3$ only attenuate apoptosis and increase cell viability in $\mathrm{H}_{2} \mathrm{O}_{2}$-treated DS and euploid neurons by $10 \%$ in which the effects were minimal to maintain most of the DS cells' morphology. $\gamma T 3$ act as a free radical scavenger by reducing ROS generated by $\mathrm{H}_{2} \mathrm{O}_{2}$. In untreated controls, DS neurons showed lower Bcl-2/Bax ratio and p53 expression compared to normal neurons, while CPKC and PKC- $\delta$ expressions were higher in DS neurons. On the other hand, pretreatment of $\gamma T 3$ in $\mathrm{H}_{2} \mathrm{O}_{2}$-treated DS neurons have reduced $\mathrm{BCl}-2 / \mathrm{Bax}$ ratio, which was not shown in euploid neurons. This suggests that pre-treatment of $\gamma T 3$ did not promote DS cell survival. Meanwhile $\gamma T 3$ and $\alpha T$ treatments without $\mathrm{H}_{2} \mathrm{O}_{2}$ as well as pre-treatment of $\gamma T 3$ and $\alpha \mathrm{T}$ induced changes in CPKC and PKC- $\delta$ expression in DS neurons suggesting interaction of $\gamma$ T3 and $\alpha$ T with PKC activity.

Conclusion: Our study suggests that $\gamma T 3$ pre-treatment are not sufficient to protect DS neurons from $\mathrm{H}_{2} \mathrm{O}_{2}{ }^{-}$ induced oxidative assault, instead induced the apoptosis process.

Keywords: Apoptosis, Down syndrome, human neurons, oxidative stress, $\gamma$-tocotrienol, vitamin $E$

\section{Introduction}

Vitamin $\mathrm{E}$ is a generic term for lipid-soluble, chain breaking antioxidants which consists of four tocopherol isomers $(\alpha, \beta, \gamma, \delta)$ and four tocotrienol isomers $(\alpha, \beta, \gamma$, $\delta)$. The tocopherol and tocotrienol isomers differ in the

\footnotetext{
* Correspondence: suemian@ppukm.ukm.my

'UKM Medical Molecular Biology Institute (UMBI), Universiti Kebangsaan

Malaysia (UKM), Kuala Lumpur, Malaysia

Full list of author information is available at the end of the article
}

number and position of methyl substitutions on the chromanol head. Although tocopherols and tocotrienols are closely related chemically, they differ in their biological effectiveness [1]. Studies have shown that vitamin E deficiency impairs cognitive performance in mice subjected to oxidative stress [2]. Meanwhile, one study found that Down syndrome (DS) children have significantly less vitamin E levels than normal children [3]; while another study showed that DS patients with
C Biomed Central

(c) 2012 Then et al; licensee BioMed Central Ltd. This is an Open Access article distributed under the terms of the Creative Commons Attribution License (http://creativecommons.org/licenses/by/2.0), which permits unrestricted use, distribution, and reproduction in any medium, provided the original work is properly cited. 
dementia have lower plasma levels of vitamin $\mathrm{E}$ than controls without DS [4]. These results suggest that intake of essential nutrients such as folate, vitamin B6, vitamin $E$, selenium, $\alpha$-lipoic acid might be important in preventing cognitive deterioration in DS and Alzheimer disease (AD) [5].

However, intervention studies of antioxidant supplementation in DS and AD have not been conclusive. A recent randomized controlled trial on antioxidant supplementation, including vitamin E for DS children did not show any significant difference in developmental outcome after a two-year research period. There was also no significant effect of antioxidant supplementation on the superoxide dismutase and glutathione peroxidase activities, on the superoxide dismutase to glutathione peroxidase ratio and on the urinary isoprostane concentrations [6]. Another recent review that looked at five different studies on antioxidants and cognitive functions revealed that only three studies examining vitamin $\mathrm{E}$ and $C$ supplements gave significantly different results-i. e. one study found a positive association with specific cognitive test, while the other two studies showed a link with global cognitive functions [7]. Other double-blind studies reported that vitamin $\mathrm{E}$ has no benefit in patients with mild cognitive impairment and Alzheimer's disease [8]. In all these trials, subjects partake high doses of vitamin E (2000 IU or $1500 \mathrm{mg}$ ) daily, which is more than the upper tolerable intake level for vitamin E (1500 IU or $1000 \mathrm{mg}$ per day) [9].

Vitamin E mainly function as free radical scavenger, but recent studies showed that tocopherols and tocotrienols have other non-antioxidant roles: $\alpha$-tocopherol $(\alpha \mathrm{T})$ was shown to modulate signal transduction and gene expression in various cell lines, while tocotrienols possess powerful neuroprotective, anti-inflammatory anti-angiogenic, anti-artherogenic, anti-cancer and cholesterol lowering properties (for a comprehensive review, refer [10]). Vitamin E has been shown to be neuroprotective in various studies: firstly in a landmark study of neurodegeneration of in vitro culture of DS neurons [11]; followed by a study that reported that $\alpha \mathrm{T}$ was able to attenuate oxidative stress-induced apoptosis in striatal neuron cultures via its free radical scavenger function [12]; while other studies showed that $\alpha$-tocotrienol protects neurons from glutamate-induced cell death by the c-src activation molecular pathway [13]. However, not many studies have address the possible pro-apoptotic tendency of vitamin $\mathrm{E}$ in neurons, especially tocotrienols, which has shown to have greater apoptotic activity towards various cancer cell lines such as mammary tumor cells and prostate tumor cells compared to tocopherols $[14,15]$. Current studies has shown that tocopherol and vitamin $\mathrm{E}$ analogues were able to induced apoptosis in murine C6 glioma cell line and Tet21N neuroblastoma cell line $[16,17]$ but not tocotrienols.

$\gamma$-Tocotrienol ( $\gamma \mathrm{T} 3)$ was reported to activate the apoptosis pathway via the mitochondrial death pathway of the Bcl-2 family proteins in pancreatic stellate cells [18], while tocotrienols was shown to be anti-proliferative in mammary epithelial cells by reducing PKC $\alpha$ (Protein Kinase C) activation [19]. Our previous studies in primary rat's astrocytes and cerebellar neuron cultures revealed that high dosage of $\gamma \mathrm{T} 3$ was cytotoxic and have a high tendency to induce the expressions of proteins that were involved in the apoptosis pathway such as Bax, p53 and p38 MAPK [20,21]. Another study also showed that high doses of vitamin $\mathrm{E}$ and vitamin $\mathrm{C}$ enhanced the toxic effect of $\mathrm{H}_{2} \mathrm{O}_{2}$ to cells [22]. Since most trials of vitamin E supplementations utilized high dosage of vitamin $\mathrm{E}$ for maximum effects, the concern for the safety of vitamin E supplementation at the molecular and cellular level has yet to be fully addressed. DS cells are known to be highly susceptible to oxidative damage compared to normal cells [23]. Genomic and functional profiling of DS neural progenitor cell line exposed to S100B suggested that dysregulation of chromosome 21 genes led to increased ROS and thereby altered transcriptional regulation of cytoprotective genes in response to oxidative stress [24]. Vitamin E treatment induced neuroinflammatory processes by increasing microglial activation in animals overexpressing S100B, which is involved in the neuropathology of DS and AD [25]. Therefore, the purpose of this study is to further investigate the effects of $\alpha \mathrm{T}$ and $\gamma \mathrm{T} 3$ in the apoptosis signaling pathway of human DS neurons as a model of oxidative stress susceptible system, while normal human neurons were used as control.

\section{Materials and methods \\ Materials}

The Malaysia Palm Oil Board (MPOB) supplied the palm $\gamma \mathrm{T} 3$ and $\alpha \mathrm{T}$ isomers of $87 \%$ and $80 \%$ purity respectively, which was isolated as described previously [26]. Culture dishes were from Nunc while antibodies (p53, Bax, Bcl-2, cPKC, PKC- $\delta, \beta$-actin) were from Santa Cruz Technologies. Reagents for 3-(4,5-dimethylthiazol-2-yl)-2,5-diphenyltetrazolium bromide (MTT) assays were from Promega while single-stranded DNA (ssDNA) Apoptosis ELISA kits were from Chemicon. All other chemicals and reagents were from Sigma unless indicated.

\section{Primary cortical neuron cultures from normal and DS fetal brain}

The cultures were established using human cortical brain tissues obtained from normal euploid and DS legally aborted fetuses at 14-21 weeks of gestation. The 
permission to use human fetal tissues was obtained from the ethics committee of the Spanish National Research Council (CSIC) (Approval date: August 6th, 2009; ref. no: SAF2009-13093-C02-02). Enriched neuron cultures were prepared as described elsewhere [27].

\section{Cell culture treatments}

Neuron cultures were incubated with varying concentrations of $\gamma \mathrm{T} 3$ and $\alpha \mathrm{T}$, with $\alpha \mathrm{T}$ as a positive control based on previous studies showing $\alpha \mathrm{T}$ having non-toxic and neuroprotective effects on neurons [12,21]. Stock solutions of $0.5 \mathrm{M} \gamma \mathrm{T} 3$ and $\alpha \mathrm{T}$ (in $100 \%$ ethanol) were first resolved overnight in fetal calf serum at $37^{\circ} \mathrm{C}$ and diluted to 100 times the final concentration with culture media containing 50\% ethanol. Final dilution of $\alpha \mathrm{T}$ and $\gamma \mathrm{T} 3$ in the cell culture contained $0.5 \%$ ethanol, which did not significantly affect cell survival (data not shown). All experiments utilized freshly prepared dilutions of $\mathrm{H}_{2} \mathrm{O}_{2}, \alpha \mathrm{T}$ and $\gamma \mathrm{T} 3$.

\section{Cytotoxicity of $\gamma \mathrm{T3}$}

The human DS neuron cultures were incubated with $\gamma \mathrm{T} 3(1-200 \mu \mathrm{M})$ for 24 hours at $37^{\circ} \mathrm{C}$. DS neurons were also given $\gamma \mathrm{T} 3$ treatment of 7 days and 14 days to determine possible cytotoxicity or protective effects of $\gamma \mathrm{T} 3$. Cytotoxicity of $\gamma \mathrm{T} 3$ and $\alpha \mathrm{T}$ was assessed by propidium iodide (PI) assay. Briefly, for PI assay, the cultures in 96 wells were stained with PI $(7 \mu \mathrm{M})$ for one hour prior to the end of the incubation period ( $24 \mathrm{~h}$. 7 days and 14 days). At the end of the incubation period, the fluorescence intensity was determined and expressed relative to cultures treated with $0.2 \%$ Triton X-100 (to permeabilize all cells). The fluorescence signal was measured by a fluorescence plate reader (Molecular Devices, USA) at 530-nm excitation / 645-nm emission to quantify cell membrane damage as described elsewhere [28].

\section{Detection of Cell Survival}

DS and euploid cortical neurons were pre-treated with varying concentrations of $\alpha \mathrm{T}$ and $\gamma \mathrm{T} 3(1-100 \mu \mathrm{M})$ for one hour at $37^{\circ} \mathrm{C}$, followed by addition of $\mathrm{H}_{2} \mathrm{O}_{2}(100$ $\mu \mathrm{M})$ to the cells and a further incubation for 24 hours at $37^{\circ} \mathrm{C}$ before cell viability and apoptosis were assessed. Cell viability was assessed using MTT assay. Briefly, the cell culture media was loaded with $0.5 \mathrm{mg} / \mathrm{mL}$ MTT to detect any decrease in the cell metabolic activity using MTT reduction assay following standard procedures [29]. Meanwhile, the rate of apoptosis was measured using the ssDNA ELISA kit as described previously [20]. In addition, cell viability was also assessed utilizing the PI assay as described above. For cell imaging, DS neuron cultures were stained with of Neu-N (neuron- specific nuclear protein) antibody to confirm the results shown by the MTT and ssDNA ELISA assay. Briefly, cells were fixed with $4 \%$ paraformaldehyde before being permeabilized with $0.25 \%$ Triton in PBS for 30 mins. The cells were then washed with PBS, followed by incubation with goat serum at room temperature to block unspecific binding site, and incubation with mouse Neu-N antibody (Chemicon, USA) in 1:200 dilution overnight at $4^{\circ} \mathrm{C}$. Subsequently, cultures were washed with PBS and incubated with anti-mouse Alexa Fluor 488 (Molecular Probes, The Netherlands) in 1:2000 dilution for 1 $\mathrm{hr}$ at room temperature. After washing with PBS, nuclei were counterstained with Hoescht before visualization under fluorescence microscope (Nikon, Japan) at $40 \times$ magnification. The intracellular production of ROS was determined using DCFH-DA assay. Non-fluorescent DCFH-DA was permeable to cell membrane and oxidation of hydroperoxides produced fluorescent 2',7'dichlorofluorescein (DCF), which was detected by fluorescence plate reader at $485 \mathrm{~nm}$ excitation/530 nm emission [30].

\section{Determination of Vitamin E Uptake by HPLC}

The uptake of $\gamma \mathrm{T} 3$ and $\alpha \mathrm{T}$ was analyzed using reversephase high performance liquid chromatography (HPLC) Fluorescent EM 330 nm, EX 294 nm detector (Shimadzu, Japan) as described previously [20]. Concentration peaks of the samples were compared with tocotrienol rich fraction (TRF) standard and the concentrations of $\alpha \mathrm{T}$ and $\gamma \mathrm{T} 3$ uptake in cells were calculated as $\mu \mathrm{M} / 10^{6}$ cells.

\section{SDS-PAGE and Western Blot}

Western blot of DS and euploid (normal) cortical neurons in various treatment groups were used to elucidate the expression of proteins involved in the apoptosis signaling pathway including p53, Bax, Bcl-2, cPKC (for detection of common isoforms PKC- $\alpha$, PKC- $\beta$ and $\mathrm{PKC}-\gamma)$ and $\mathrm{PKC}-\delta$; while $\beta$-actin were used as housekeeping protein and loading control. A maximum protective dosage of $10 \mu \mathrm{M} \gamma \mathrm{T} 3$ and $\alpha \mathrm{T}$ was used to test if this concentration could induce apoptosis in DS and euploid neurons. The western blots were performed as previously described.

\section{Statistical Analysis}

Each experiment of cultures in microplates was carried out in triplicate wells with at least three independent cultures. The data were reported as mean \pm SD of at least three experiments. Comparison between groups was made by the Student's t test, one-way ANOVA and Bonferroni adjustment as well as two-way ANOVA for multiple comparisons. $\mathrm{p}<0.05$ was considered as statistically significant for Student t-test whereas $\mathrm{p}<0.0001$ was considered as statistically significant for multi-factor comparisons. 


\section{Results and discussion}

From the PI assays, $1 \mu \mathrm{M}$ and $10 \mu \mathrm{M}$ of $\gamma \mathrm{T} 3$ and $\alpha \mathrm{T}$ maintained cell viability but did not improve cell survival when it was added to the DS culture for 14 days, $\gamma \mathrm{T} 3$ was cytotoxic to DS cortical neurons at concentration $\geq 100 \mu \mathrm{M}$ compared to $\alpha \mathrm{T}$, with increased apoptosis of $25-35 \%$ and $5-8 \%$ respectively [Figure 1 (a)]. For neurons incubated with $\gamma \mathrm{T} 3$, more apoptotic cells were observed at $50 \mu \mathrm{M}$, and at $100 \mu \mathrm{M}$ almost all of the cells undergo apoptosis. From Figure 1 (b), a short 1 day incubation of $\gamma \mathrm{T} 3$ at $10 \mu \mathrm{M}$ and $100 \mu \mathrm{M}$ in DS neurons was only able to reduced apoptosis by $10 \%$. The previous landmark study has shown that $\alpha \mathrm{T}$ was able to attenuate apoptosis and improve cell viability [11], whereas prolonged incubation time of $\gamma \mathrm{T} 3$ up to 14 days increased membrane damage and apoptosis to DS neurons, as detected from the PI assay at a dose dependent manner. Similar to our previous studies, long term incubation of $\gamma \mathrm{T} 3$ was shown to be cytotoxic to neurons at high dose $(\geq 100 \mu \mathrm{M})$ while $\alpha \mathrm{T}$ showed minor toxic effects to human neurons as illustrated in Figure 1 (a) and Figure 1 (b) $[20,21]$. Fluorescence detection of DCF showed that $\gamma \mathrm{T} 3$ act as a free radical scavenger by reducing ROS generated by $\mathrm{H}_{2} \mathrm{O}_{2}$ in a dose dependent (a)

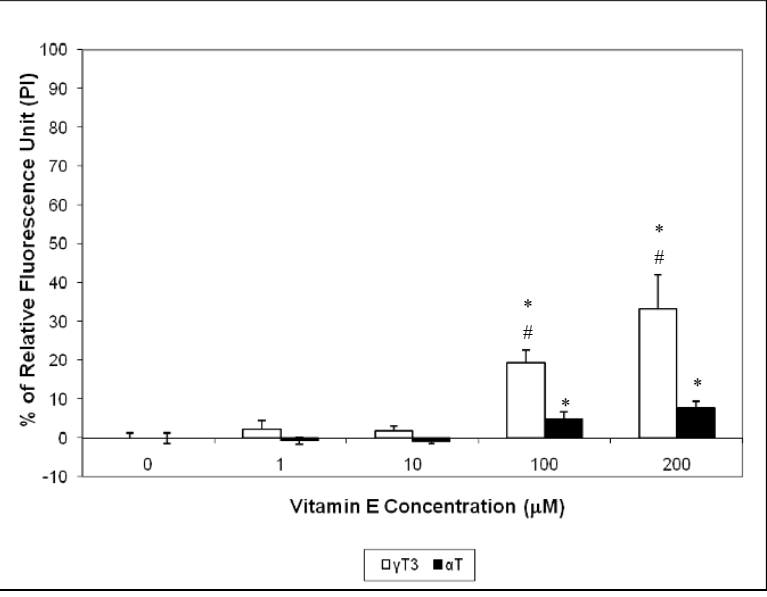

(c)

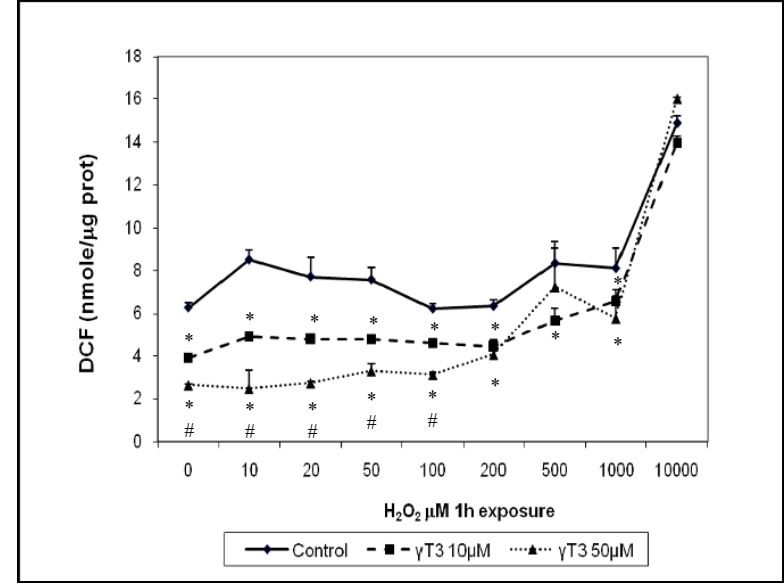

(b)

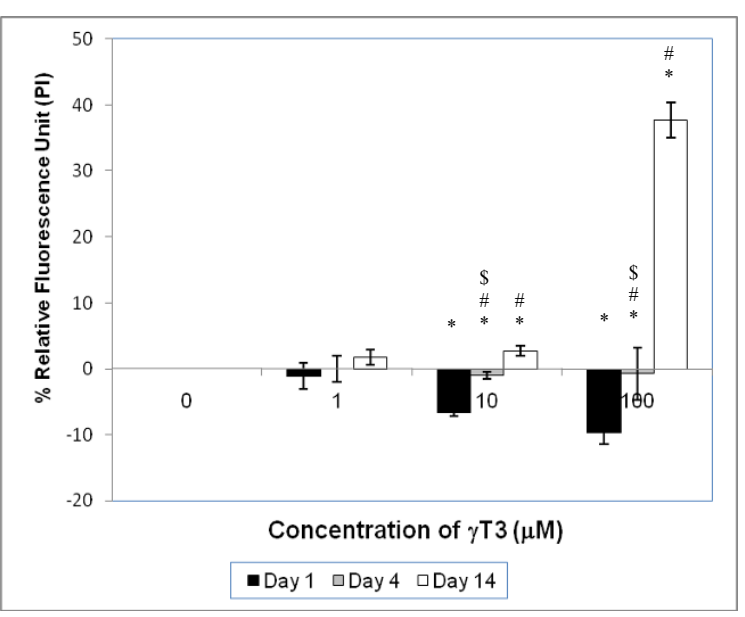

(d)

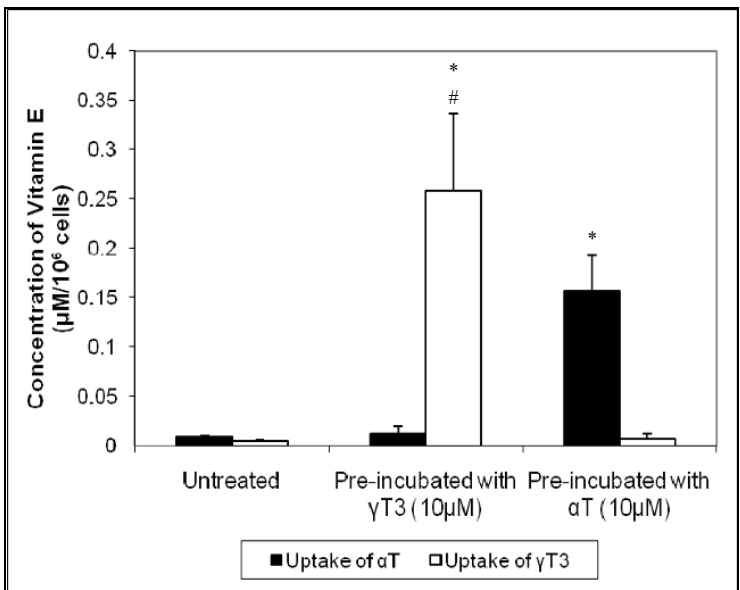

Figure 1 (a) The effects of $\alpha$-tocopherol ( $\alpha \mathrm{T})$ and $\gamma$-tocotrienol $(\gamma \mathrm{T} 3)$ towards DS neuronal cell death for 14 days in vitro as detected by Propidium lodide (PI) assay. *Denotes $P<0.05$ compared to control while ${ }^{\#}$ denotes $P<0.05$ when $\gamma$ T3 was compared to $\alpha T$ at their corresponding concentration. The data are presented as mean \pm SD, $n=6$. (b) The effects of $\gamma$ T3 at various incubation periods ( 1 day, 4 days and 14 days). ${ }^{*}$ Denotes $P<0.05$ compared to the control, while ${ }^{\#}$ denotes $P<0.05$ compared to day 1 and ${ }^{\$}$ denotes $P<0.05$ compared to day 4. The data are presented as mean $\pm \mathrm{SD}, \mathrm{n}=3$. (c) The effects of $\gamma$ T3 on ROS generated by $\mathrm{H}_{2} \mathrm{O}_{2}$ in DS neurons with intracellular accumulation of hydroperoxides after one hour exposure to the indicated concentration of $\mathrm{H}_{2} \mathrm{O}_{2}$ measured by DCFH oxidation to DCF. ${ }^{*}$ Denotes $\mathrm{P}<0.05$ compared to control while \# denotes $\mathrm{P}<0.05$ compared to $10 \mu \mathrm{M} \gamma \mathrm{\gamma}$. The data are presented as mean \pm SD, $\mathrm{n}=3$. (d) Uptake of $\alpha$ tocopherol $(\alpha T)$ and $\gamma$-tocotrienol $(\gamma T 3)$ in human cortical neurons measured by HPLC. The cellular uptake of $\gamma T 3$ and $\alpha T$ was significantly higher than the untreated control, with the uptake of $\gamma \top 3$ significantly higher than that of $\alpha T$. ${ }^{*}$ Denotes $P<0.05$ compared to the control, while \# denotes $P<0.05$ when $\gamma$ T3 uptake of $\gamma$ T3 incubated cultures were compared with $\alpha \top$ uptake of $\alpha T$ incubated cultures. The data are presented as mean $\pm \mathrm{SD}, \mathrm{n}=3$. 
manner at concentration $\leq 1000 \mu \mathrm{M}$ of $\gamma \mathrm{T} 3$ after one hour $\mathrm{H}_{2} \mathrm{O}_{2}$ exposure [Figure 1 (c)]. The HPLC analysis revealed that the uptake of $\gamma \mathrm{T} 3$ was higher compared to the uptake of $\alpha \mathrm{T}$ in neurons [Figure 1 (d)]. The absorption of $\alpha \mathrm{T}$ had been associated to ATP-binding cassette $(\mathrm{ABC})$ transporter (MDR1) which acts as a cellular exporter of tocopherols to ApoA-I and HDL by ABCA1-dependent and ABCA1-independent processes $[31,32]$. Hence, this may explain why high doses of $\alpha \mathrm{T}$ did not exhibit toxicity to neurons, as $\alpha \mathrm{T}$ was effluxed from the cells by ABC transporter 1 (MDR1) to eliminate excess $\alpha \mathrm{T}$. On the other hand, $\gamma \mathrm{T} 3$ was not selectively transported by TTP. Thus, excess $\gamma$ T3 was not being effluxed from the cells, leading to the accumulation of $\gamma \mathrm{T} 3$ that might exacerbate cell death and contribute to the possible toxicity of $\gamma \mathrm{T} 3$ at high dose.

In both DS and euploid neurons, the pre-treatment of $\gamma \mathrm{T} 3$ and $\alpha \mathrm{T}$ at concentration $\leq 50 \mu \mathrm{M}$ was able to reduce cell death induced by $\mathrm{H}_{2} \mathrm{O}_{2}$ [Figure 2 (a) and Figure 3 (a)] and increase cell viability [Figure 2 (b) and Figure 3 (b)]. Figure 2 (c) and Figure 3 (c) shows that both pre-treatments of up to $10 \mu \mathrm{M} \gamma \mathrm{T} 3$ and $50 \mu \mathrm{M} \alpha \mathrm{T}$ were able to attenuate apoptosis in $\mathrm{H}_{2} \mathrm{O}_{2}$-induced DS and euploid neurons respectively. However, the effectiveness of $\gamma \mathrm{T} 3$ and $\alpha \mathrm{T}$ pre-treatment was more pronounced in euploid neurons compared to DS neurons, as two-way ANOVA analysis showed that vitamin E isomer type and concentration contributed significantly to cell viability and apoptosis rate in euploid neurons but not in DS neurons. This indicated that the protective effect of the vitamin $\mathrm{E}$ in euploid neurons is dose and isomer type dependent, while protective effects of vitamin $\mathrm{E}$ in DS neurons is not dependent on dose and isomer type. Figure 4 shows the morphology of $\mathrm{H}_{2} \mathrm{O}_{2}$ treated DS neurons as stained by Neu-N, a marker for differentiated neurons [33] which had undergone apoptosis; pre-treatment with $10 \mu \mathrm{M}$ of $\alpha \mathrm{T}$ or $\gamma \mathrm{T} 3$ retained some of the neurons' viability but cell morphologies were not fully maintained. Reduced Neu-N expression in differentiated neurons indicated perturbed cell morphology induced by $\mathrm{H}_{2} \mathrm{O}_{2}$ assault, which pre-treatment of either $\alpha \mathrm{T}$ or $\gamma \mathrm{T} 3$ were not substantial enough to protect cells from oxidative assault. However, comparatively $\alpha \mathrm{T}$ seems to be more protective to the DS neurons than $\gamma \mathrm{T} 3$ as more cells were stained with Neu-N, although the staining was dim. This is not surprising since the previous study has shown that in vitro DS cortical neuron culture had higher sensitivity to $\mathrm{H}_{2} \mathrm{O}_{2}$-induced oxidative damage compared to euploid neurons [27]. $\mathrm{H}_{2} \mathrm{O}_{2}$ directly induces cellular damage and has been reported to induce parallel apoptosis and autophagy [34], making it more difficult for $\alpha \mathrm{T}$ and $\gamma \mathrm{T} 3$ to protect the cells especially if the pre-treatment incubation period was short. Since our previous studies have shown that high dose of vitamin $\mathrm{E}$ compounds the toxic effect of $\mathrm{H}_{2} \mathrm{O}_{2}$, here we further investigate whether non-lethal doses of high concentration $\alpha \mathrm{T}$ and $\gamma \mathrm{T} 3$ will further exacerbate the detrimental effects of $\mathrm{H}_{2} \mathrm{O}_{2}$ via the mitochondrial Bcl-2 family pathway or the PKC signalling pathway as both $\mathrm{cPKC}$ and $\mathrm{PKC}-\delta$ are redox sensitive and were reported to be involved in the initiation of apoptosis signalling $[35,36]$.

From our investigation, euploid neurons showed a completely different protein expression profile compared to DS neurons. In the control group, DS neurons were shown to have lower Bcl-2/Bax ratio and p53 expression compared to euploid neurons, while $\mathrm{cPKC}$ and PKC- $\delta$ expressions were higher in DS neurons. Figure 5 (a) (i), Figure 5 (a) (ii) and Figure 6a revealed that for DS neurons, pre-treatment of $\gamma \mathrm{T} 3$ followed by $\mathrm{H}_{2} \mathrm{O}_{2}$ has significantly lower Bcl-2/Bax ratio than the controls, whereas other treatment showed changes which were not statistically significant. This result suggests that $\gamma \mathrm{T} 3$ does not contribute to the survival of DS neurons under $\mathrm{H}_{2} \mathrm{O}_{2}$ assault via the $\mathrm{Bcl}-2 / \mathrm{Bax}$ heterodimer complex formation. However, the analysis of Western blot for the euploid neurons in Figure 5 (b) (i), Figure 5 (b) (ii) and Figure 6 (a) showed a different picture: Bcl-2/Bax ratio increased significantly in euploid neurons when neurons were pre-treated with either $\gamma \mathrm{T} 3$ or $\alpha \mathrm{T}$ followed by $\mathrm{H}_{2} \mathrm{O}_{2}$ which suggested that $\gamma \mathrm{T} 3$ pre-treatment attenuated apoptosis and improved cell survival of normal euploid neurons. However, p53 expression was not significantly different across various treatments in both DS and euploid neurons, as depicted in Figure 5 (a) (iii), Figure 5 (b) (iii) and Figure 6 (b). Nevertheless, the comparison of p53 expression between DS and euploid neurons showed lower p53 expression in DS neurons for these treatment groups: control, $\mathrm{H}_{2} \mathrm{O}_{2}, \gamma \mathrm{T} 3$ followed by $\mathrm{H}_{2} \mathrm{O}_{2}$ and $\gamma \mathrm{T} 3$ treatments only. Taking it all together, these results show that lower $\mathrm{Bcl}-2 / \mathrm{Bax}$ ratio DS neurons in the untreated groups, was in agreement with the results from previous study which reported that fetal DS neurons had increased Bax and p53 expressions mediated by the transcription factor est- 2 when treated with $\mathrm{H}_{2} \mathrm{O}_{2}$ [37]. On the other hand, another study reported that APO-1, caspase- 3 and Bcl-2 protein expression levels were unaltered in the fetal DS neurons [38]. A previous study also stated that incubation of $\alpha \mathrm{T}$ induced the up-regulation of Bcl-2 as preventive effects from neuronal cell death [39]. Thus, treatment of only $\alpha \mathrm{T}$ and $\gamma \mathrm{T} 3$ without the presence of $\mathrm{H}_{2} \mathrm{O}_{2}$ in human neuron did not show pro-apoptosis tendency (from the $\mathrm{Bcl}-2 / \mathrm{Bax}$ ratio and $\mathrm{p} 53$ expression) compared to rat cerebellar culture as reported previously [21].

Aberrant expression of PKC signalling has been reported in fetal DS post-mortem tissues [40], while DS patients' fibroblast was reported to be hyposensitive to 
(a)

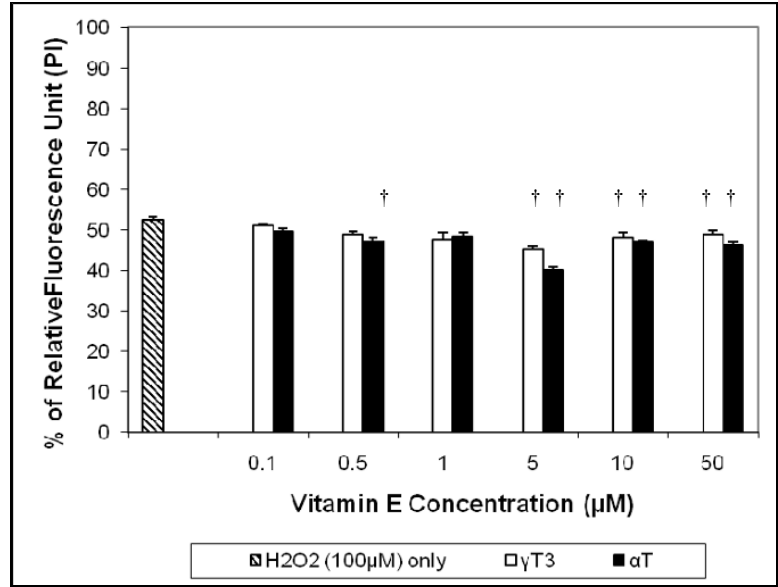

(b)

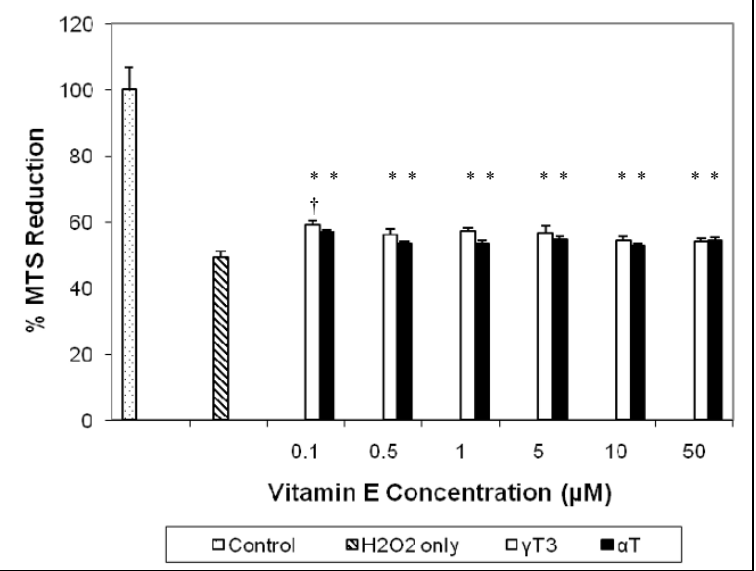

(c)

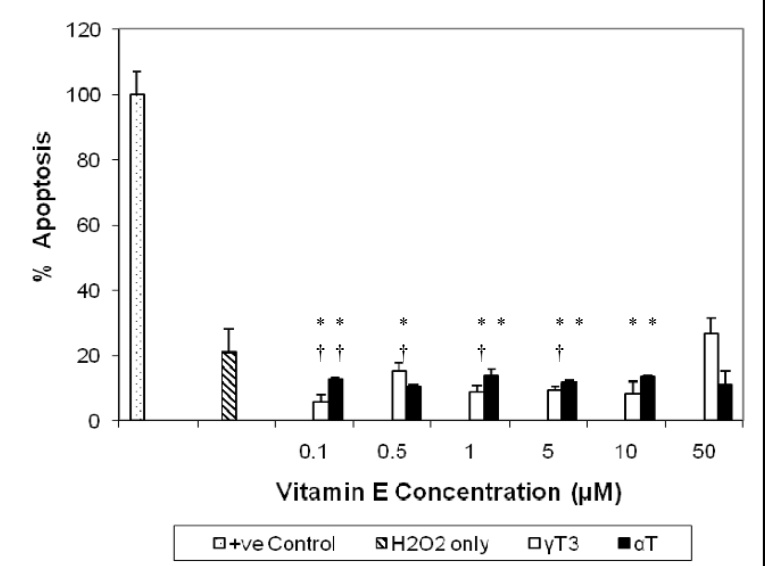

Figure 2 The effects of $\alpha$-tocopherol ( $\alpha \mathrm{T})$ and $\gamma$-tocotrienol $(\gamma \mathrm{T} 3)$ against $\mathrm{H}_{2} \mathrm{O}_{2}$-induced cell death in human DS neuron cultures, whereby (a) the cell death was determined using propidium iodide (PI) assay, (b) the cell viability was determined using MTT assay, (c) the apoptosis assay was determined using ELISA kits for ssDNA. The neurons were pre-treated with varying concentrations of $\alpha T$ and $\gamma \top 3$ for one hour before the exposure to $100 \mu \mathrm{M} \mathrm{H}_{2} \mathrm{O}_{2}$ for 24 hours at $37^{\circ} \mathrm{C}$. ${ }^{*}$ Denotes $\mathrm{P}<0.05$ compared to control, + denotes $\mathrm{P}<0.0001$ compared to $\mathrm{H}_{2} \mathrm{O}_{2}$. The data are presented as mean $\pm \mathrm{SD}$, from 3 independent experiments of triplicate wells $(n=9)$. One-way ANOVA showed that there are significant differences between groups, $F_{13,83}=14.47, P<0.001$. Meanwhile, two-way ANOVA showed both types of vitamin $E$ isomer and vitamin $E$ concentration are not significant factors contributing to the cell survival and no significant interaction between types of vitamin $\mathrm{E}$ isomer and vitamin $\mathrm{E}$ concentration $\left(\mathrm{F}_{5,71}=0.45\right)$.

PKC [41]. However, both studies did not specify the location of PKC isoforms involvement. From previous study, cPKC was shown to be activated when exposed to oxidative stress in neuronal death induced by ischemia, hypoxia and exitotoxicity [42], whereas other studies revealed that an increase in PKC- $\delta$ expression was needed for glutamate-induced neuronal death [43], Parkinson's disease model [44] and AGE-induced neuronal death [45] as well as $\mathrm{H}_{2} \mathrm{O}_{2}$-induced oxidative stress [46]. Across the various treatment groups, the expression of cPKC was higher in DS neurons compared to euploid neurons. However, the cPKC expression of DS neurons was down-regulated in all other treatment groups $(\gamma \mathrm{T} 3$ followed by $\mathrm{H}_{2} \mathrm{O}_{2}, \gamma \mathrm{T} 3$, $\alpha \mathrm{T}$ followed by $\mathrm{H}_{2} \mathrm{O}_{2}$, and $\alpha \mathrm{T}$ ), as shown in Figure 5 (a) (iv) and Figure 6 (c). From Figure 5 (a) (v) and Figure 6 (d), DS neurons showed a 2- fold increase of PKC- $\delta$ expression in $\mathrm{H}_{2} \mathrm{O}_{2}$-treated neurons, suggesting an accumulation of PKC- $\delta$ in the cytosol, which signified pro-apoptotic activities in neurons [44] were suppressed by the pre-treatment of $\gamma \mathrm{T} 3$, while the pre-treatment of $\alpha \mathrm{T}$ did not alter PKC- $\delta$ expression. In normal euploid neurons, $\mathrm{H}_{2} \mathrm{O}_{2}$ induced increased cPKC expression [Figure 5 (b) (iv) and Figure 6 (c)] but suppressed PKC- $\delta$ [Figure 5 (b) (v) and Figure 6 (d)]. Pre-treatment of $\gamma \mathrm{T} 3$ suppressed the cPKC expression but elevated the PKC- $\delta$ expression; while the pre-treatment of $\alpha \mathrm{T}$ was found to increase the cPKC expression but down-regulated PKC- $\delta$ expression [Figure 6 (c) and Figure 6 (d)]. $\alpha \mathrm{T}$ has been known to inhibit PKC- $\alpha$ activities $[47,48]$ which was not shown in euploid neurons pre-treated with $\alpha \mathrm{T}$ in Figure 5 (b) (iv) and Figure 6 (c). Meanwhile a high concentration of $\alpha \mathrm{T}(500 \mu \mathrm{M})$ 

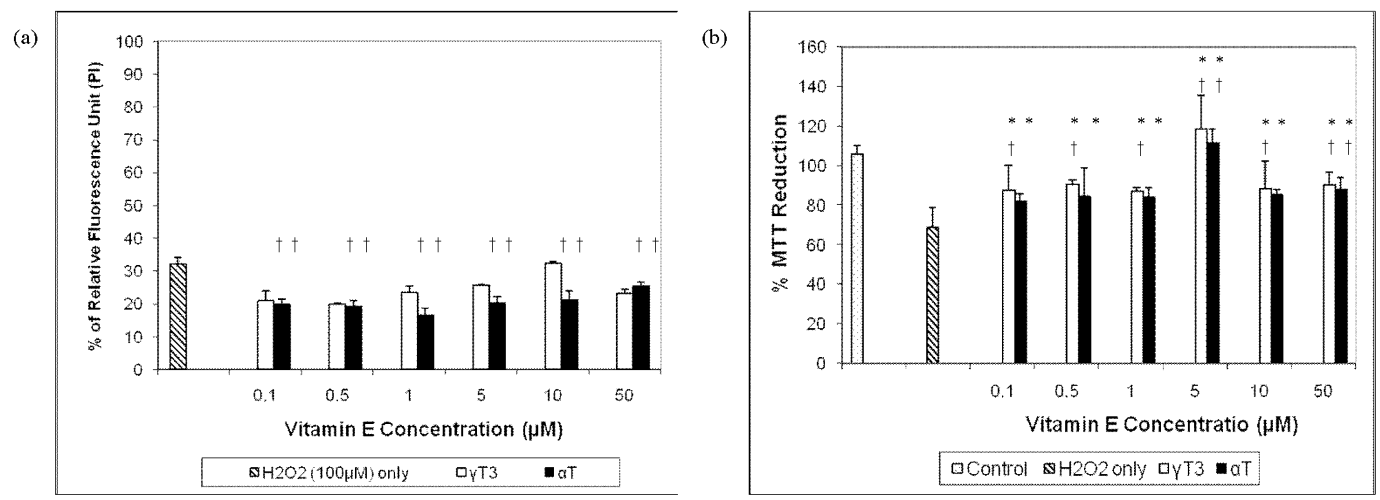

(c)

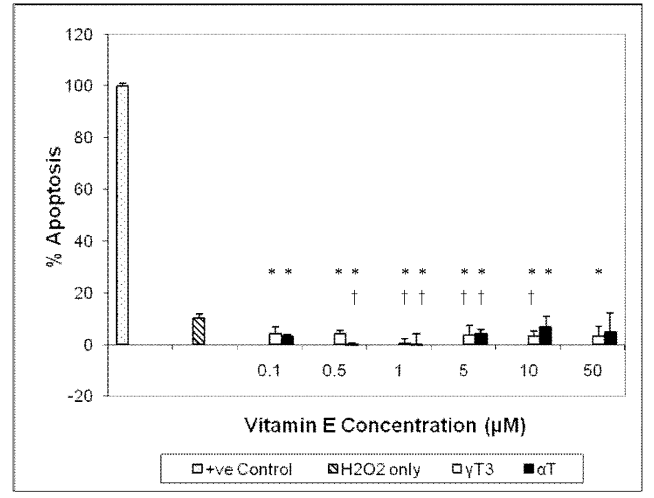

Figure 3 The effects of $\alpha$-tocopherol ( $\alpha \mathrm{T})$ and $\gamma$-tocotrienol $(\gamma \mathrm{T} 3)$ against $\mathrm{H}_{2} \mathrm{O}_{2}$-induced cell loss in human euploid neuron cultures, whereby (a) the cell death was determined using propidium iodide (PI) assay, (b) the cell viability was determined using MTT assay, and (c) the apoptosis assay was determined using ELISA kits for ssDNA. The neurons were pre-treated with varying concentrations of $\alpha T$ and $\gamma \mathrm{T} 3$ for one hour before the exposure to $100 \mu \mathrm{M} \mathrm{H}_{2} \mathrm{O}_{2}$ for 24 hours at $37^{\circ} \mathrm{C}$. * Denotes $\mathrm{P}<0.05$ compared to control, $\uparrow$ denotes $\mathrm{P}<0.0001$ compared to $\mathrm{H}_{2} \mathrm{O}_{2}$. The data are presented as mean $\pm \mathrm{SD}$, from 3 independent experiments of triplicate wells $(n=9)$. One-way ANOVA showed that there are significant differences between groups, $F_{13,83}=9.81, P<0.001$. Two-way ANOVA showed both types of vitamin $E$ isomer and vitamin $\mathrm{E}$ concentration are significant factors contributing to the cell survival and no significant interaction between types of vitamin $\mathrm{E}$ isomer and vitamin E concentration $\left(\mathrm{F}_{5,71}=27.15, \mathrm{P}<0.0001\right)$
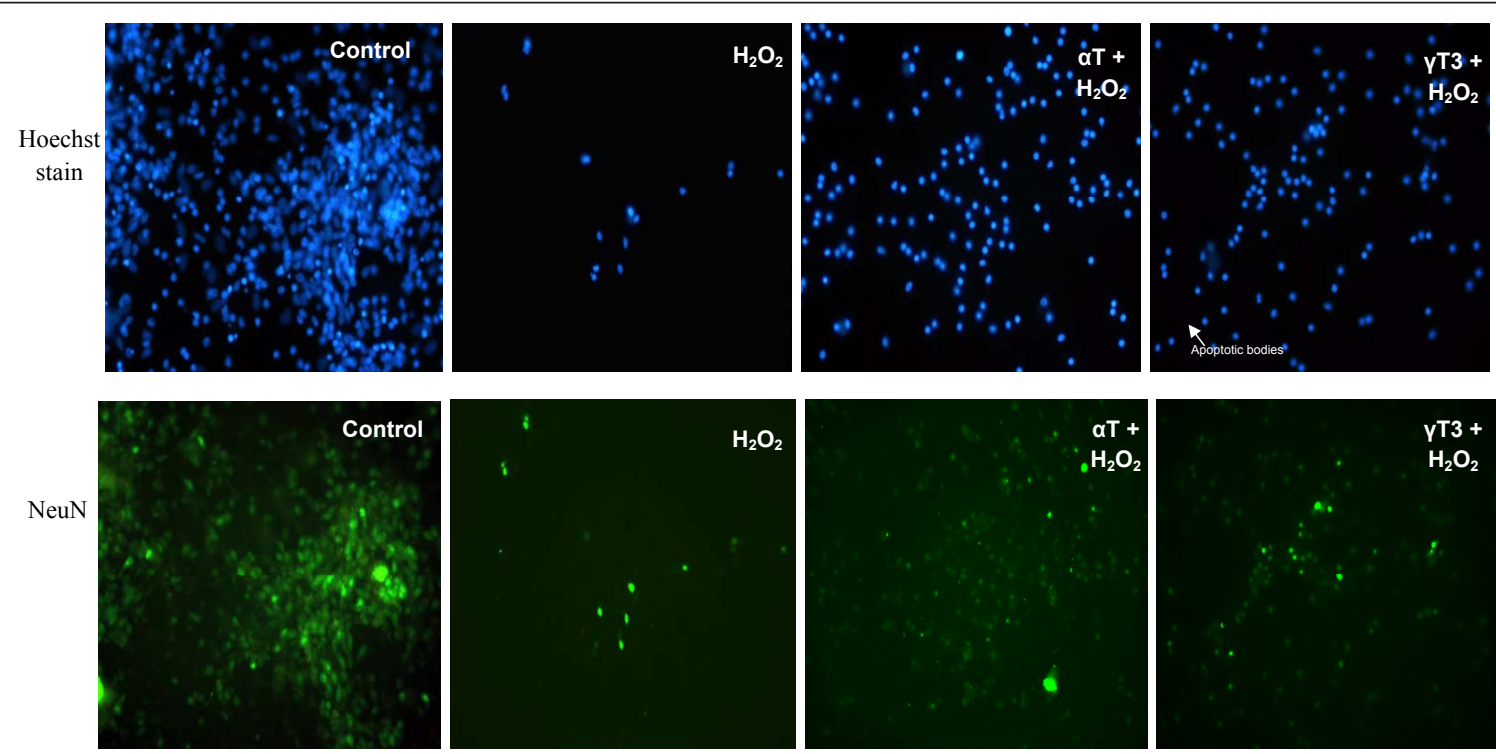

Figure 4 Fluorescence image of DS neurons stained with anti Neu-N antibody in various treatments: control, $100 \mu \mathrm{M}$ of $\mathrm{H}_{2} \mathrm{O}_{2}$ only, $10 \mu \mathrm{M}$ of $\alpha \mathrm{T}$ or $\gamma \mathrm{T} 3$ pre-treatment followed by $\mathrm{H}_{2} \mathrm{O}_{2}$ exposure 
has been shown to inhibit PKC- $\delta$ activation in AGEinduced neuronal death [45] in which lower dose of $\alpha \mathrm{T}$ pretreatment in euploid neurons showed similar result [Figure 5 (b) (v) and Figure 6 (d)]. However, the incubation of only $\gamma \mathrm{T} 3$ also showed a decrease in cPKC, similar to a previous study which showed that $\gamma \mathrm{T} 3$ suppressed PKC- $\alpha$ expression [19]. This suggests that besides functioning as an antioxidant, $\gamma \mathrm{T} 3$ might also play a role in modulating PKC- $\delta$ expression as $\mathrm{PKC}-\delta$ is a redox sensitive molecule.

\section{Conclusion}

This study revealed that in DS neurons, even though $\gamma \mathrm{T} 3$ pre-treatment provided initial slight improvement in neuron viability, the protection from both $\alpha \mathrm{T}$ and $\gamma \mathrm{T} 3$ pre-treatment was not substantial to protect DS neurons from $\mathrm{H}_{2} \mathrm{O}_{2}$ assault. Furthermore, pre-treatment of $\gamma \mathrm{T} 3$ would reduce the $\mathrm{Bcl}-2 / \mathrm{Bax}$ ratio that indicates cell survival while $\alpha \mathrm{T}$ pre-treatment did not suppress pro-apoptotic PKC- $\delta$ expression in the cells. However, in non-oxidative stress condition, $\alpha \mathrm{T}$ and $\gamma \mathrm{T} 3$ did not exert strong pro-apoptosis tendency in human DS and euploid neurons compared to our previous studies in rat neurons [21]. DS neurons has been shown to have chronic overexpression of S100B, in which oxidation of S100B preferentially induced the neurotrophic processes (which is beneficial for cell survival and differentiation) over neuroinflammation processes. However treatment with antioxidants such as vitamin $\mathrm{E}$ interrupts this feedback and leads to increase glial activation and cell death [25]. This may explain the reason why in DS neurons, $\alpha \mathrm{T}$ and $\gamma \mathrm{T} 3$ at the concentrations used in this study may aggravate cellular damages in a highly susceptible

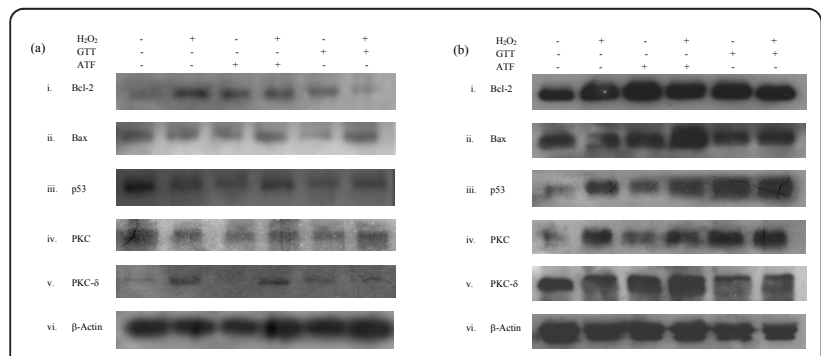

Figure $5 \mathrm{Bcl}-2, \mathrm{Bax}, \mathrm{p} 53, \mathrm{cPKC}$ and PKC- $\delta$ were differentially expressed in euploid and DS neurons which were given various treatments in the following fashion: untreated control, incubation of neurons with $\mathrm{H}_{2} \mathrm{O}_{2}$ for 24 hours $\left(\mathrm{H}_{2} \mathrm{O}_{2}\right)$, incubation of neurons with $\gamma \mathrm{T} 3(10 \mu \mathrm{M})$ for 24 hours $(\gamma \mathrm{T} 3)$, one hour of $\gamma \mathrm{T} 3(10 \mu \mathrm{M})$ pre-treatment in neurons followed by $\mathrm{H}_{2} \mathrm{O}_{2}$ incubation for 24 hours $\left(\gamma \mathrm{T} 3+\mathrm{H}_{2} \mathrm{O}_{2}\right)$, incubation of neurons with $\alpha \mathrm{T}(10 \mu \mathrm{M})$ for 24 hours $(\alpha \mathrm{T})$ and one hour of $\alpha \mathrm{T}$ $(10 \mu \mathrm{M})$ pre-treatment in neurons, followed by $\mathrm{H}_{2} \mathrm{O}_{2}$ incubation for $\mathbf{2 4}$ hours $\left(\alpha \mathrm{T}+\mathrm{H}_{2} \mathrm{O}_{2}\right)$. (a) Western blot of $\mathrm{BCl}-2$, Bax, p53, cPKC and PKC in DS neurons; (b) Western blot of the same proteins in euploid neurons.

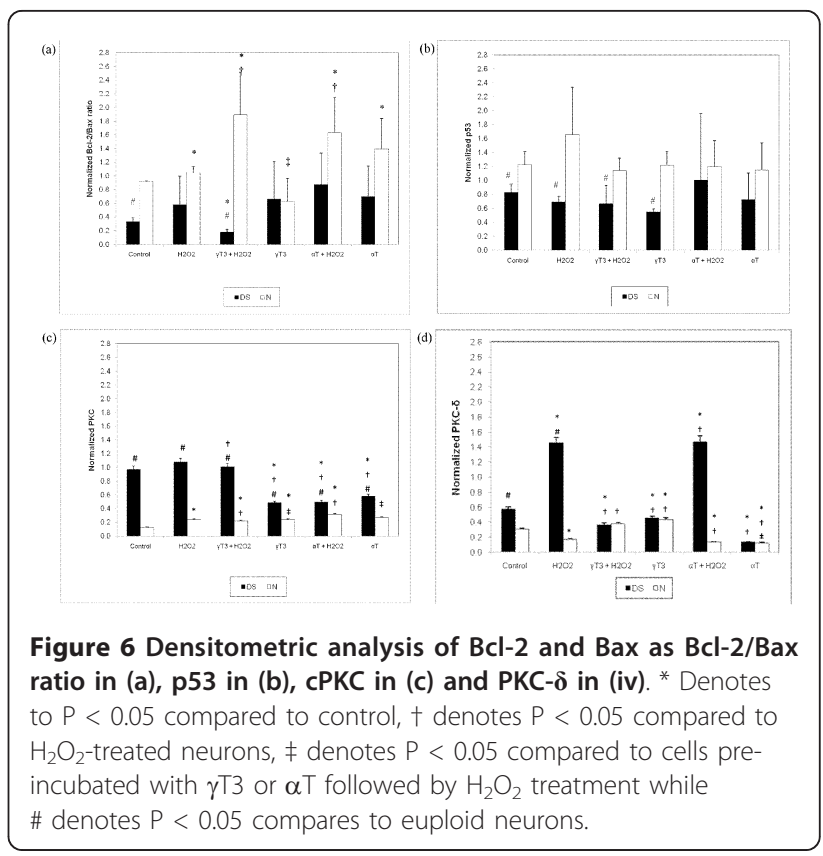

neuronal cell model subjected to oxidative stress. Our present results further underlie the importance of more study to be done on the safety of vitamin E supplementation in neurodegenerative diseases such as DS and AD. Although $\gamma \mathrm{T} 3$ act as a free radical scavenger which could quench ROS generated from $\mathrm{H}_{2} \mathrm{O}_{2}$, it may also synergistically induce apoptosis and autophagy through the mitochondrial death pathway, including the Bcl-2 family proteins [49]. Meanwhile, our study also showed that $\alpha \mathrm{T}$ has a different mechanism of action compared to $\gamma \mathrm{T} 3$, which remains to be further elucidated.

\section{Acknowledgements}

We are grateful to Dr Santiago Barambio, Yolanda Trejo and Raquel Lopez from Tutor Medica Clinics, Barcelona, and Dr Nuria Toran from Hospital de la Vall d'Hebron, Barcelona, for their assistance in providing the tissue samples for this work. This study was funded by the Ministry of Science, Technology and Innovation Malaysia under the Intensified Research Prioritized Area (IRPA) grant 06-02-02-002/PR0008/09-07, SAF2009-13093-C02-02 from MICINN and RD06/0013/1004 from ISCIII, Spain.

\section{Author details}

'UKM Medical Molecular Biology Institute (UMBI), Universiti Kebangsaan Malaysia (UKM), Kuala Lumpur, Malaysia. ${ }^{2}$ Institut d'Investigacions Biomèdiques de Barcelona (IIBB), CSIC-IDIBAPS, Barcelona, Spain. ${ }^{3}$ Department of Biochemistry, Faculty of Medicine, Universiti Kebangsaan Malaysia (UKM), Kuala Lumpur, Malaysia. ${ }^{4}$ Malaysian Palm Oil Board, Bangi, Selangor, Malaysia.

\section{Authors' contributions}

SMT carried out the most of the experiments, performed the statistical analysis and drafted the manuscript. WZWN and MM played a major role in the experimental procedures of this study and revised the manuscript. CS carried out the cell imaging work and help revised the manuscript. Meanwhile, GMT extracted the vitamin E isomers and tested the purity of the vitamin $E$ isomers. All authors have read and approved the final manuscript. 


\section{Competing interests}

The authors declare that they have no competing interests.

Received: 2 November 2011 Accepted: 5 January 2012

Published: 5 January 2012

\section{References}

1. Yoshida Y, Niki E, Noguchi N: Comparative study on the action of tocopherols and tocotrienols as antioxidants: chemical and physical effects. Chem Phys Lipids 2003, 123:63-75.

2. Mihalick SM, Ortiz D, Kumar R, Rogers E, Shea TB: Folate and vitamin E deficiency impair cognitive performance in mice subjected to oxidative stress: differential impact on normal mice and mice lacking apolipoprotein E. Neuromolecular Med 2003, 4:197-201.

3. Cengiz M, Seven M: Vitamin and mineral status in Down syndrome. Trace Elem Electrolytes 2000, 17:156-160

4. Jackson CV, Holland AJ, Williams CA, Dickerson JW: Vitamin E and Alzheimer's disease in subjects with Down's syndrome. J Ment Defic Res 1999, 32:479-484.

5. Theil R, Fowkes SW: Can cognitive deterioration associated with Down syndrome be reduced? Med. Hypotheses 2005, 64:524-532.

6. Ellis JM, Tan HK, Gilbert RE, Muller DPR, Henley W, Moy R, Pumphrey R, Ani C, Davies S, Edwards V, Green H, Salt A, Logan S: Supplementation with antioxidants and folinic acid for children with Down's syndrome: randomized controlled trial. BMJ 2008, 336:594-597.

7. Ancelin ML, Christen Y, Ritchie K: Is antioxidant therapy a viable alternative for mild cognitive impairment? Examination of the evidence. Dement Geriatr Cogn Disord 2007, 24:1-19.

8. Isaac MG, Quinn R, Tabet N: Vitamin E for Alzheimer's disease and mild cognitive impairment. Cochrane Database Syst Rev.

9. Arab L, Barr SI, Becking GC, Beecher GR, Borra ST, Burk RF, Carriquiry AL, Chan AC, Devaney BL, Dwyer JT, Erdman JJW, Habicht J-P, Jacob RA, Jialal I, Kimbrough RD, Kolonel LN, Krinsky NI, Kuhnlein HV, Marshall JR, Mayne ST, Messing RB, Miller SA, Munro IC, Murphy SP, Pastides H, Prentice RL, Rodricks JV, Rosenberg IH, Schwarz KB, Steinberg D, al e: Dietary Reference Intakes: Vitamin C, Vitamin E, Selenium and Carotenoids. Washington, D. C., Institute of Medicine; 2000.

10. Sen CK, Khanna S, Roy S: Tocotrienols: Vitamin E beyond tocopherols. Life Sci 2006, 78:2088-2098,

11. Busciglio J, Yankner B: Apoptosis and increased generation of reactive oxygen species in Down's syndrome neurons in vitro. Nature 1995, 378:776-779.

12. Osakada F, Hashino A, Kume T, Katsuki H, Kaneko S, Akaike A Neuroprotective effects of alpha-tocopherol on oxidative stress in rat straital cultures. Eur J Pharmacol 2003, 465:15-22.

13. Sen C, Khanna S, Roy S, Packer L: Molecular basis of vitamin E action: tocotrienol potently inhibits glutamate-induced pp60cSrc kinase activation and death of HT4 neuronal cells J. Biol Chem 2000, 275:13049-13055.

14. Wali VB, Sylvester PW: Synergistic antiproliferative effects of gammatocotrienol and statin treatment on mammary tumor cells. Lipids 2007, 42:1113-1123.

15. Kumar KS, Raghavan M, Hieber K, Ege C, Mog S, Parra N, Hildabrand A, Singh V, Srinivasan V, Toles R, Karikari P, Petrovics G, Seed T, Srivastava S, Papas A: Prefencial radiation sensitization of prostate cancer in nude mice by nutraceutical antioxidant c-tocotrienol. Life Sci 2006, 78:2099-2104.

16. Betti M, Minelli A, Canonico B, Castaldo P, Magi S, Aisa MC, Piroddi M, Di Tomaso V, Galli F: Antiproliferative effects of tocopherols (vitamin E) on murine glioma C6 cells: homologue-specific control of PKC/ERK and cyclin signaling. Free Radic Biol Med 2006, 41:464-472.

17. Gogvadze V, Norberg E, Orrenius S, Zhivotovsky B: Involvment of Ca2+ and ROS in alpha-tocopheryl succinate-iduced mitochondrial permeabilization. Int J Cancer 2010, 127:1823-1832.

18. Rickmann M, Vaquero EC, Malagelada JR, Molero X: Tocotrienols induce apoptosis and autophagy in rat pancreatic stellate cells through the mitochondrial death pathway. Gastroenterol 2007, 132:2518-2532.

19. Sylvester PW, Mclntyre BS, Gapor A, Briski KP: Vitamin E inhibition of normal mammary epithelial cell growth is associated with a reduction in protein kinase Calpha activation. Cell Prolif 2001, 34:347-357.
20. Mazlan M, Sue Mian T, Mat Top G, Zurinah Wan NW: Comparative effects of alpha-tocopherol and gamma-tocotrienol against hydrogen peroxide induced apoptosis on primary-cultured astrocytes. I Neurol Science 2006, 243:5-12.

21. Then SM, Mazlan M, Gapor MT, Wan Ngah WZ: Is vitamin E toxic to neurons? Cell Mol Neurobiol 2009, 29:485-496.

22. Shang F, Lu M, Dudek E, Reddan J, Taylor A: Vitamin C and vitamin E restore the resistance of GSH-depleted lens cells to $\mathrm{H}_{2} \mathrm{O} 2$. Free Radic Biol Med 2003, 34:521-530.

23. Zana M, Janka Z, Kalman J: Oxidative stress: a bridge between Down's syndrome and Alzheimer's disease. Neurobiol Aging 2007, 28:648-676.

24. Esposito G, Imitola J, Lu J, Filippis D, Scuderi C, Ganesh VS, Folkerth R, Hecht J, Shin SJ, Luvone T, Chesnut J, Steardo L, Sheen V: Genomic and functional profiling of human Down syndrome neural progenitors implicates S100B and aquaporin 4 in cell injury. Human Mol Gen 2008, 17:440-457.

25. Bialowas-McGoey LA, Lesicka A, Whitaker-Azmitia PM: Vitamin E increases S100B-mediated microGLIA activation in an S100B-overexpressing mouse model of pathological aging. Glia 2008, 56:1780-1790.

26. Choo YM, Ma AN, Basiron Y: A method of chromotagraphic isolation for vitamin E isomers. 2001, European Patent EP1122250; United States Patent 6656358.

27. Sebastia J, Cristofol R, Pertusa M, Vilchez D, Toran N, Barambio S, RodriguezFarre E, Sanfeliu C: Down's syndrome astrocytes have greater antioxidant capacity than euploid astrocytes. Eur J Neurosci 2004, 20:2355-2366.

28. Rosa R, Sanfeliu C, Suñol C, Pomés A, Rodríguez-Farré E, Schousboe A, Frandsen A: The mechanism for hexachlorocyclohexane-induced cytotoxicity and changes in intracellular $\mathrm{Ca} 2+$ homeostasis in cultured cerebellar granule cell neurons is different for the $\mathrm{c}$ and $\mathrm{d}$ isomers. Toxicol Appl Pharmacol 1997, 142:31-39.

29. Hansen MB, Nielsen SE, Berg K: Re-examination and further development of a precise and rapid dye method for measuring cell growth/cell kill. J Immunol Methods 1989, 119:203-210.

30. Sebastia J, Cristofol R, Martin M, Rodriquez-Farre E, Sanfeliu C: Evaluation of fluorescent dyes for measuring intracellular glutathione content in primary cultures of human neurons and neuroblastoma SH-SY5Y. Cytometry Part A 2003, 51:16-25.

31. Reboul E, Trompier D, Moussa M, Klein A, Landrier J, Chimini G, Borel P: ATP-binding cassette transporter A1 is significantly involved in the intestinal absorption of alpha- and gamma-tocopherol but not in that of retinyl palmitate in mice. Am J Clin Nutr 2009, 89:177-184.

32. Oram J, Vaugham A, Stocker R: ATP-binding cassette transporter A1 mediates cellular secretion of alpha-tocopherol. J Biol Chem 2001, 276:39898-39902.

33. Mullen RJ, Buck CR, Smith AM: NeuN, a neuronal specific nuclear protein in vertabrates. Development 1992, 116:201-211.

34. Zhang H, Kong X, Kang J, Su J, Zhong J, Sun L: Oxidative stress induces parallel autophagy and mitochondria dysfunction in human glioma U251 cells. Toxicol Sci 2009, 110:376-388.

35. Majumder P, Mishra N, Sun X, Bharti A, Kharbanda S, Saxena S, Kufe D: Targeting of protein kinase $C$ delta to mitochondria in the oxidative stress response. Cell Growth Differ 2001, 12:465-470.

36. Yamaguchi T, Miki Y, Yoshida K: Protein kinase $C \delta$ activates IkB-kinase a to induce the $\mathrm{p} 53$ tumor suppressor in response to oxidative stress. Cell Signalling 2007, 19:2088-2097.

37. Helguera P, Pelsman A, Pigino G, Wolvetang E, Head E, Busciglio J: est-2 promotes the activation of a mitochondrial death pathway in Down's syndrome neurons. Neurobiol Dis 2005, 25:2295-2303.

38. Engidawork E, Balic N, Juranville JF, Fountoulakis M, Dierssen M, G L: Unaltered expression of Fas (CD95/APO-1), caspase-3, BCl-2 and annexins in brains of fetal Down syndrome: evidence against increased apoptosis. J Neural Transm Suppl 2001, 61:149-162.

39. Numakawa Y, Numakawa T, Matsumoto T, Yagasaki Y, Kumamaru E, Kunugi H, Taguchi T, Niki E: Vitamin E protected cultured cortical neurons from oxidative stress-induced cell death through activation of mitogenactivated protein kinase and phosphatidylinositol 3-kinase. J Neurochem 2006, 97:1191-1202.

40. Peyrl A, Weitzdoerfer R, Gulesserian T, Fountoulakis M, Lubec G: Aberrant expression of signaling-related proteins 14-3-3 gamma and RACK1 in fetal Down syndrome brain (trisomy 21). Electrophoresis 2002, 23:152-157. 
41. Govoni S, Bergamaschi S, Gasparini L, Quaglia C, Racchi M, Cattaneo E, Binetti G, Bianchetti A, Giovetti F, Battaini F, Trabuechi M: Fibroblasts of patients affected by Down's syndrome oversecrete amyloid precursor protein and are hyporesponsive to protein kinase C stimulation. Neurology 1996, 47:1069-1075.

42. Durkin JP, Tremblay R, Chakravarthy B, Mealing G, Morley P, Small D, Song $D$ : Evidence that the early loss of membrane protein kinase $C$ is a necessary step in the excitatory amino acid-induced death of primary cortical neurons. J Neurochem 1997, 68:1400-1412.

43. Choi B, Hur E, Lee J, Jun D, Kim K: Protein kinase C delta-mediated proteasomal degradation of MAP kinase phosphatase-1 contributes to glutamate-induced neuronal cell death. J Cell Sci 2006, 119:1329-1340.

44. Kanthasamy AG, Anantharam V, Zhang D, Latchoumycandane C, Jin H, Kaul S, Kanthasamy A: A novel peptide inhibitor targeted to caspase-3 cleavage site of a proapoptotic kinase protein kinase $\mathrm{C}$ delta (PKC $\delta$ ) protects against dopaminergic neuronal degeneration in Parkinson's disease models. Free Radic Biol \& Med 2006, 41:1578-1589.

45. Nitti M, d'Abramo C, Traverso N, Verzola D, Garibotto G, Poggi A, Odetti P, Cottalasso D, Marinari UM, Maria A, Pronzato MA, Domenicotti C: Central role of PKC-delta in glycoxidation-dependent apoptosis of human neurons. Free Radic Biol Med 2005, 38:846-856.

46. Carvour M, Song C, Kaul S, Anantharam V, Kanthasamy A, Kanthasamy A: Chronic low-dose oxidative stress induces caspase-3-dependent PKCdelta proteolytic activation and apoptosis in a cell culture model of dopaminergic neurodegeneration. Ann N Y Acad Sci 2008, 1139:197-205.

47. Ricciarelli R, Tasinato A, Clement S, Ozer NK, Boscoboinik D, Azzi A: alphaTocopherol specifically inactivates cellular protein kinase $\mathrm{C}$ a by changing its phosphorylation state. Biochem J 1998, 334:243-249.

48. Carter CA, Kane CJ: Therapeutic potential of natural compounds that regulate the activity of protein kinase C. Curr Med Chem 2004 11:2883-2902.

49. Yap WN, Chang PN, Han HY, Lee DTW, Ling MT, Wong YC, Yap YL: gammatocotrienol suppresses prostate cancer cell proliferation and invasion through multiple signalling pathways. Brit J Cancer 2008, 99:1832-1841.

doi:10.1186/1743-7075-9-1

Cite this article as: Then et al: $\gamma$-Tocotrienol does not substantially protect DS neurons from hydrogen peroxide-induced oxidative injury. Nutrition \& Metabolism 2012 9:1.

\section{Submit your next manuscript to BioMed Central and take full advantage of:}

- Convenient online submission

- Thorough peer review

- No space constraints or color figure charges

- Immediate publication on acceptance

- Inclusion in PubMed, CAS, Scopus and Google Scholar

- Research which is freely available for redistribution

Submit your manuscript at www.biomedcentral.com/submit 